\title{
Peran Brand Equity Terhadap Customer Value dan Repurchase Intention Produk Kartu Simpati Di Kota Pekanbaru
}

\author{
RIO RAMADHIAN; SUSI HENDRIANI; SRI RESTUTI \\ Program Pascasarjana Manajemen Universitas Riau \\ J1. Pattimura No. 9, Gobah (0761) 24410 \\ E-mail : ramadhianmails@yahoo.com
}

\begin{abstract}
The role of brand equity to customer value and repurchase intentions of Simpati card products in Pekanbaru City. The purpose of this study is to understand the influence of every dimension of brand equity which consists of brand awareness, perceived quality, brand loyalty, and brand association, whether to customer value or to repurchase intentions directly. The data are collected by using questionnaires, derived from 200 Simpati Telkomsel card users in Pekanbaru City, determined by using purposive sampling. The main tool of data analysis is AMOS 22. The result of this study shows that all models are good and indicate being able to be replicated. This is also supported by good measurement model. The relation model of brand equity to customer value tends to be good, but togehter with customer value, they are in a good model category to repurchase intentions. Among four dimensions of brand equity used in this study, only brand associations is the most important dimension variable to customer value. Whereas for repurchase intentions, only brand loyalty has an important role. Although perceived quality and brand awareness don't have important role, whether to customer value or repurchase intentions, but both can strengthen other two dimensions. Perceived quality indicates a better role to strengthen brand loyalty and associations. While, brand awareness only strengthens brand associations.
\end{abstract}

Keywords: brand equity, brand awareness, perceived quality, brand loyalty dan associations, customer value and repurchase intentions

Telkomsel sebagai pemimpin pasar percaya bahwa brand yang mereka miliki memiliki ekuitas yang tinggi pada masyarakat. Hal tersebut dengan diperolehnya penghargaan mengenai merek, salah satunya ditahun 2014 ini Telkomsel mendapatkan Gold Champion of Indonesia WOW Brand di Hotel Ritz Carlton Jakarta tanggal 11 September 2014.

Merek-merek terbaik dapat memberikan jaminan kualitas bagi konsumennya. Merek lebih dari sekedar simbol, identitas dari perusahaan tersebut atau nama dari perusahaan tersebut, merek merupakan sebuah janji perusahaan yang menciptakan hubungan emosional antara perusahaan, pelanggan, dan publik.

Dengan memperhatikan penjelasan di atas maka menjadi menarik untuk meneliti peran brand equity dengan menggunakan empat dimensinya yakni brand loyalty, brand awareness, perceived quality, dan brand associations, terhadap customer value dan repurchase intention produk Simpati Telkomsel di Kota Pekanbaru.

Dari dimensi brand equity sebagai mana model Aaker, hanya 4 dimensi (selain dimensi other proprietary of brand assets), yang relevan bagi pelanggan (Aaker, 1997). Hal ini dikarenakan assetaset lain yang berkaitan dengan merek (seperti hak paten dan saluran distribusi), tidak berhubungan secara langsung dengan konsumen.

Rumusan pertanyaan masalah dalam penelitian adalah sebagai berikut: Bagaimana pengaruh setiap dimensi brand equity yang terdiri dari brand loyalty, brand awareness, perceived quality, dan brand associations terhadap customer value produk kartu Simpati di kota Pekanbaru?; Bagaimana pengaruh setiap dimensi brand equity yang terdiri dari brand loyalty, brand awareness, perceived quality, dan brand associations secara langsung terhadap repurchase intention pelanggan produk kartu Simpati di kota 
Pekanbaru?; Bagaimana pengaruh customer value terhadap repurchase intention pelanggan kartu Simpati Telkomsel di kota Pekanbaru?

Merek merupakan suatu persepsi dari sekumpulan infomasi dan pengalaman yang terintegrasi yang membedakan suatu perusahaan dan/atau produk yang ditawarkannya dari suatu kompetisi (Duncan, 2002). Sedangkan American Marketing Association/AMA (Keller, 2003 dalam Suryani, 2006) mendefinisikan merek sebagai nama, istilah, tanda simbol, rancangan, atau beberapa ciri lainnya, yang mengidentifikasi barang atau jasa dari seorang atau sekelompok penjual sebagai pembeda dari para penjual lainnya.

Aaker (1991) dalam Purba (2010) mendefinisikan brand equity sebagai sekumpulan asset dan liabilities merek yang terkait pada suatu merek, nama dan simbolnya, yang menambah atau mengurangi nilai suatu perusahaan dan/atau nilai konsumen, yang diberikan oleh suatu produk. Sementara Knapp (2001) dalam Mulyati (2013) mendefinisikan ekuitas merek sebagai totalitas dari persepsi merek, mencakup kualitas relatif dari produk dan jasa, kinerja keuangan, loyalitas pelanggan, keputusan dan keseluruhan penghargaan terhadap merek.

Secara umum definsi-definisi tersebut mengarah ke suatu hal yang sama, bahwa suatu merek ternyata memiliki nilai yang lebih dari sekedar nama bagi suatu produk, melainkan suatu asset yang juga harus dikelola oleh perusahaan dan memiliki nilai yang tidak mudah diukur seperti goodwill nama baik. Brand equity perlu dibangun, karena semakin kuat ekuitas sebuah merek, semakin banyak pula nilai tambah yang bias diperoleh produsen maupun customer.

Terdapat tiga titik pandang yang berbeda untuk pertimbangan brand equity, yaitu : perspektif berdasarkan pelanggan, perspektif finansial dan perspektif kombinasi. Perspektif berdasarkan pelanggan menggolongkan dua konsep multidimensional, yaitu kekuatan merek dan nilai merek (Srivastava dan Shocker, 1991 dalam Suryani, 2006). Kekuatan merek berdasarkan pada persepsi dan perilaku dari pelanggan yang menghargai merek yang memiliki daya saing berbeda dan berkelanjutan. Sedangkan nilai merek merupakan outcome financial dari kemampuan manajemen untuk mempengaruhi kekuatan merek melalui suatu tindakan stratejik yang memberikan profit yang superior pada saat ini dan masa mendatang.

Brand awareness didefinisikan sebagai kemampuan seorang pembeli untuk mengenali atau mengingat, bahwa suatu merek merupakan bagian dari suatu kategori produk tertentu (Aaker, 1991 dalam Suryani, 2006). Menciptakan dan menjaga kesadaran pelanggan akan suatu merek merupakan suatu hal yang penting karena dengan adanya kesadaran terhadap suatu merek, maka pelanggan secara sadar akan mempertimbangkan merek dimaksud diantara berbagai merek yang memungkinkan untuk dibeli pelanggan. Brand awareness juga berkenaan dengan kemampuan para pelanggan untuk mengingat dan memahami merek dimaksud, sebagai suatu bagian dari produk tertentu.

Dalam kondisi pasar yang saat ini serba turbulensi sebagai akibat banyak merek dalam suatu kategori produk, dan dengan berbagai tipe product family. Sulit bagi suatu perusahaan untuk mencapai keunggulan daya saing, apabila tidak ada pembedaan yang nyata antara merek perusahaan dengan para pesaingnya.Salah satu aspek keunggulan daya saing perusahaan adalah berkaitan dengan kualitas, yaitu kualitas yang dirasakan oleh pelanggan. Adalah kondisi yang objektif apabila D'alessandro dan Owens (2000) dalam Suryani (2006) menggambarkan situasi pasar saat ini berada dalam situasi "perang merek".

Oliver (1999) dalam Suryani (2006) menjelaskan bahwa ada empat tingkatan loyalitas pelanggan yaitu loyalitas kognitif, loyalitas afektif,

p.ISSN: $2407-800 X \quad$ e.ISSN: 2541-4356 
Loyalitas konatif, dan loyalitas aksi. Pada tingkatan loyalitas kognitif, produk lebih disukai dari alternatif lainnya berdasarkan informasi yang diterima pelanggan tentang atribut produk (tingkatan kinerja atribut). Pada tingkatan lebih lanjut - loyalitas afektif, sikap suka pada suatu merek didasarkan pada kejadian penggunaan yang terakumulasi karena hadirnya nilai-nilai yang diharapkan pelanggan.

Sebuah merek yang telah mencapai ekuitas merek tinggi merupakan asset yang berharga bagi perusahaan. Untuk itu, mempertahankan dan meningkatkan ekuitas merek bukan pekerjaan mudah, karena yang dihadapi adalah ekspektasi pelanggan. Konsumen akan merasa familiar dengan nama merek yang pertama masuk ke pasar. Sekalipun merek-merek yang masuk belakangan berkinerja lebih baik. Ini akan mengarah kepada terciptanya kesetiaan yang lebih besar pada merek pertama dan produsen. Kesetiaan pelanggan menjadi kunci sukses tidak hanya dalam jangka pendek tetapi keunggulan bersaing yang berkelanjutan.

$$
\text { Walaupun brand equity }
$$

didefinisikan dalam berbagai perspektif yang berbeda, namun pada dasarnya ada dua perspektif yang diadopsi, yaitu nilai merek bagi perusahaan dan nilai merek bagi pelanggan.

Dalam perspektif nilai bagi perusahaan, mereka memandang brand equity dalam suatu perspektif financial. Perspektif financial dimaksud berdasarkan pada arus kas dimasa mendatang yang dimasa mendatang yang diskonto semakin meningkat, dan menghasilkan suatu revenue dari produk-produk bermerek yang lebih besar dibandingkan dengan revenue yang dihasilkan oleh produk-produk yang tidak bermerek (Simon dan Sullivan, 1993).

Suatu merek haruslah mampu menyediakan benefit dan/atau nilai bagi para pelanggan. Harapan pelanggan akan adanya suatu benefit atau nilai, disebabkan karena adanya pengorbanan yang mereka pertukarkan dalam memperoleh merek dimaksud. Menurut Duncan (2002) ada lima benefit atau nilai dari suatu merek (brand relationship) bagi pelanggan. Pertama, mengurangi resiko (less risk). Kedua, keputusan yang lebih sedikit (fewer decisions). Ketiga, biaya perpindahan yang lebih sedikit (fewer swiching costs). Keempat, efisiensi pembelian yang lebih besar (greater buying efficiency). Kelima, asosiasi yang meningkat (increased association).

Ajzen dan Fishbein dalam (Tjiptono, 2005) dalam Yusnidar (2014) menjelaskan bahwa riset-riset dibidang psikologi menyimpulkan bahwa purchase intention berkemampuan prediktif sangat besar terhadap pembelian aktual, terutama apabila ada hubungan antara dua dari empat kategori berikut : tindakan (misalnya pembelian untuk keperluan sendiri), target (contohnya tipe merek spesifik), konteks (tipe toko, tingkat harga dan kondisi lainnya) dan waktu (seminggu, sebulan, setahun). Purchase intention dipandang sebagai segala sesuatu yang ditentukan oleh komponen sosial atau norma subyektif yang dipertimbangkan dan digabungkan untuk mengevaluasi dan menyeleksi berbagi alternatif perilaku guna memenuhi kebutuhan hidup. Hubungan tersebut digambarkan pada kerangka penelitian di bawah ini :

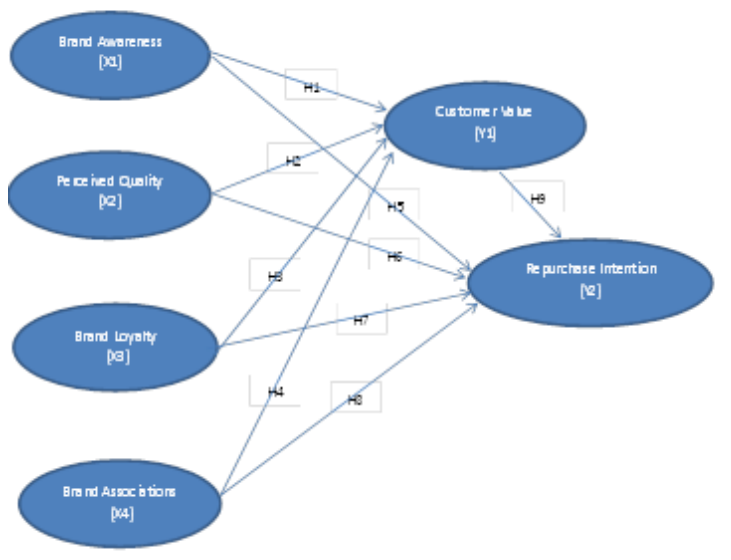

Sumber : Aaker (1996) dalam Suryani (2006)

p.ISSN: 2407-800X e.ISSN: 2541-4356 


\section{METODE}

Penelitian dilakukan di Kota Pekanbaru dengan memfokuskan pada empat mal utama di kota Pekanbaru, yakni Mal Pekanbaru, Mal Ciputra, MTC Giant Panam, dan Mal SKA.

Adapun variabel yang dianalisa dalam penelitian ini yaitu :

a. Variabel Eksogen (X) dalam penelitian ini meliputi brand loyalty, brand awareness, perceived quality, dan brand associations.

b. Variabel Intervening (Y1) dalam penelitian ini adalah Customer Value.

c. Variabel Endogen (Y2) dalam penelitian ini adalah purchase intention.

Dalam penelitian ini, besarnya sampel disesuaikan dengan model analisis yang digunakan yaitu Structural Equation Model (SEM). Berkaitan dengan hal tersebut, ukuran sampel untuk SEM adalah 100 - 200 sampel (Ferdinand, 2006) dalam Yunidar (2014). Dalam penelitian ini jumlah responden yang diperoleh sebanyak 200 responden, yang diperoleh dari perkalian indikator dengan jumlah parameter yaitu, 27 $\mathrm{x} 7=189$.

Penentuan sampel terpilih dengan metode mall intercept pada empat mal utama di kota Pekanbaru, yakni Mal Pekanbaru, Mal Ciputra, MTC Giant Panam, dan Mal SKA.

Dan penyebaran kuesioner ini memperhatikan beberapa kriteria diantaranya:

a. Telah menggunakan simPATI minimal 6 bulan.

b. Kartu simPATI telah digunakan sebagai kartu primary dalam berkomunikasi.

c. Berdomisili di kota Pekanbaru.

d. Usia pengguna dalam minimal 17 tahun.

Jenis dan sumber data yang digunakan dalam penelitian ini adalah data primer dan data sekunder yaitu :

\section{a. Data Primer}

Data yang diperoleh secara langsung dari para pelanggan yang menggunakan KARTU As dan simPATI berdasarkan daftar pertanyaan. b. Data Sekunder. Data yang diperoleh dari dokumen Telkomsel, Annual
Report, laporan-laporan penelitian, majalah dan web site internet yang mendukung data primer.

Prosedur pengumpulan data yang dipakai dalam penelitian ini dilakukan dengan interview (wawancara) dengan kuisioner (daftar pertanyaan). Kuesioner yang akan digunakan dalam penelitian ini dilakukan dengan terstruktur (structured question) yang terdiri atas 3 jenis :

a. Multiple choice question, yang merupakan pertanyaan dengan beberapa alternatif jawaban yang sudah disediakan dan responden diminta memilih satu atau lebih alternatif tersebut.

b. Dichotomous question, dimana responden hanya diminta menjawab salah satu diantara dua alternatif jawaban, yaitu "Ya" atau "Tidak".

c. Scales, yaitu suatu bentuk pertanyaan yang menggunakan skala dalam mengukur dan mengetahui tingkat persetujuan adalah skala likert. Skala likert merupakan pembobotan nilai pada setiap pilihan jawaban dalam kuesioner (Agusty Ferdinand, 2006 dalam Yusnidar : 2014).

Dalam penelitian ini penulis melakukan analisa distribusi frekuensi dan mean (nilai rata-rata) untuk memberikan gambaran mengenai kecenderungan tanggapan responden terhadap variabel penelitian. Dalam melakukan analisis tersebut, maka penulis merumuskan sebuah interval acuan yang menjadi landasan pengambilan keputusan.

Dengan menggunakan Structural Equation Model (SEM), peneliti dapat mempelajari hubungan structural yang diekspresikan oleh seperangkat persamaan. Ghozali (2008) menjelaskan model persamaan struktur Structural Equation Model (SEM) adalah generasi kedua teknik analisis multivariate yang memungkinkan peneliti menguji hubungan antar variabel yang komplek baik recursive maupun nonrecursive untuk memperoleh gambaran mengenai keseluruhan model. Structural Equation Model (SEM) dapat menguji 
secara bersama-sama model structural (structural model) dan model pengukuran (measurement model).

Tujuan dilakukan pretest kuesioner adalah untuk menghindari munculnya measurement error ketika kuesioner penelitian digunakan sebagai alat untuk pengumpulan data. Sehingga pretest diharapkan menghasilkan alat pengumpul data (kuesioner) yang lebih baik dan semakin memperkecil kemungkinan error yang ditimbulkannya..

\section{HASIL}

Hasil evaluasi kecocokan model pengukuran, baik terkait tiga puluh empat variabel indikator maupun ke enam variabel konstruk (latent), dinyatakan baik. Dalam hal ini terdapat indikasi, bahwa kondisi repurchase intentions perlu mendapat penjelasan sebesar 11 persen dari exogenous variable(s) lain yang belum diikut-sertakan dalam model penelitian ini. Kemampuan menjelaskan sebesar 0,89 (89 persen) mengindikasikan model struktural II merupakan model pada tingkat kelayakan yang baik.

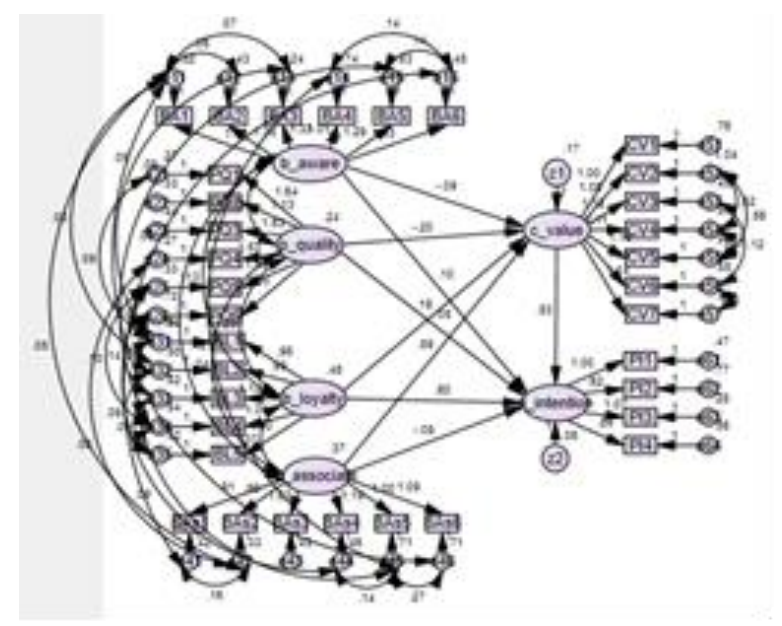

(a)

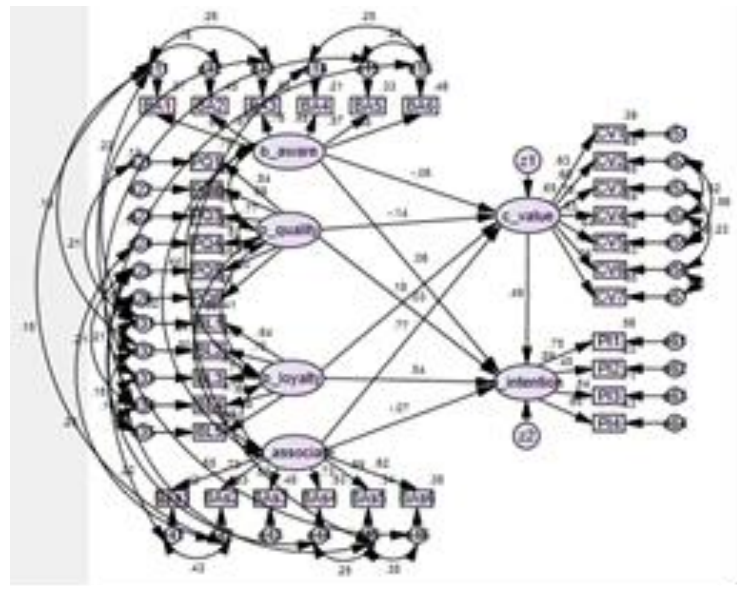

(b)

Gambar 1.
Hasil Pembentukan Model Penelitian
Pelanggan Simcard simPATI: (a)
unstandardardized, (b) standardized
estimate

\section{PEMBAHASAN}

Berdasarkan hasil efek langsung dan efek tidak langsung, pada akhirnya dapat dihitung efek total (total effect) yang dihasilkan. Dengan demikian, hasil perhitungan dapat memperjelas peran customer value memperantarai setiap pola hubungan suatu variabel exogenous terhadap variabel endogenous (repurchase intentions).

Apabila dilakukan perbaikan pada beberapa hal yang ada pada setiap variable, maka dapat dimungkinkan peran berbagai variabel dimaksud dapat sejalan dengan konsep teoritik yang ada. Hal ini akan ditelaah lebih lanjut pada pembahasan dan implikasi penelitian.

Adanya pembelian ulang dari pelanggannya merupakan hal yang diharapkan. Dengan adanya pembelian secara berulang, maka diharapkan dapat terbangun hubungan jangka panjang yang berkesinambungan antara produsen dengan pelanggannya. Seberapa sering frekuensi pembelian ulang, akan sangat tergantung dari karakteristik produk.

Customer value yang dihadirkan simcard Telkomsel pada para pelanggannya di Kota Pekanbaru, masih berada pada 
kategori yang medium (sedang), walaupun ada kecenderungan bergerak kearah yang tinggi. Hal ini terutama karena karena rasa senang para pelanggan ketika menggunakan simcard simPATI. Hal ini didukung pula oleh biaya penggunaan simcard yang masih dapat diterima serta dirasa lebih bernilai. Sehingga biaya penggunaan simcard simPATI yang berlaku saat ini dirasa lebih ekonomis.

Pola hubungan antara brand awareness dengan repurchase intentions, sejalan dengan konseptualisasi penelitian. Tetapi tidak sejalan pada pola hubungan antara brand awareness dengan customer value.

Dalam hal ini, pola hubungan antara perceived quality dengan repurchase intentions, sejalan dengan konseptualisasi penelitian. Akan tetapi tidak sejalan pada pola hubungan antara perceived quality dengan customer value.

Hubungan yang terbangun pada kedua pola tersebut, sejalan dengan konseptualisasi penelitian. Tetapi hanya terjadi hubungan yang bermakna/penting antara brand loyalty dengan repurchase intentions.

Pola hubungan antara brand associations dengan customer value, sejalan dengan konseptualisasi penelitian. Tetapi tidak sejalan pada pola hubungan antara brand associations dengan repurchase intentions.

Apabila mengacu pada fakta hubungan yang terbangun pada ke empat dimensi ekuitas merek yang digunakan pada penelitian ini, maka perceived quality dapat berperan secara tidak langsung terhadap repurchase intentions dengan memperkuat keberadaan dua dimensi lainnya. Dalam hal ini perceived quality akan semakin berperan baik dan penting apabila diarahkan untuk mendorong penguatan brand loyalty maupun brand associations. Sedangkan brand awareness lebih memiliki kecenderungan hanya untuk semakin mengokohkan brand associations.

\section{SIMPULAN}

Berdasarkan hasil pembahasan penelitian, maka dapat ditarik beberapa kesimpulan sebagai berikut:

1. Hubungan antara setiap dimensi brand equity dengan customer value pada pengguna kartu simPATI di Kota Pekanbaru :

a. Semakin tinggi brand awareness, dapat semakin menurunkan customer value. Dalam hal ini brand awareness dinilai tidak berperan penting bagi customer value.

b. Semakin tinggi perceived quality, dapat semakin menurunkan customer value. Dalam hal ini perceived quality dinilai tidak berperan penting bagi customer value.

c. Semakin tinggi brand loyalty, dapat semakin mempertinggi customer value. Dalam hal ini brand loyalty dinilai tidak berperan penting bagi customer value.

d. Semakin tinggi brand associations, dapat semakin mempertinggi customer value. Dalam hal ini brand associations dinilai berperan penting bagi customer value.

2. Hubungan antara setiap dimensi brand equity dengan repurchase intentions pada pengguna kartu simPATI di Kota Pekanbaru :

a. Semakin tinggi brand awareness, dapat semakin meningkatkan repurchase intentions. Dalam hal ini brand awareness dinilai tidak berperan penting bagi repurchase intentions.

b. Semakin tinggi perceived quality, dapat semakin meningkatkan repurchase intentions. Dalam hal ini perceived quality dinilai tidak berperan penting bagi repurchase intentions.

c. Semakin tinggi brand loyalty, dapat semakin meningkatkan repurchase intentions. Dalam hal ini brand loyalty dinilai berperan penting bagi repurchase intentions. 
d. Semakin tinggi brand associations, dapat semakin menurunkan repurchase intentions. Dalam hal ini brand associations dinilai tidak berperan penting bagi repurchase intentions.

Semakin meningkat customer value, maka dapat semakin mempertinggi repurchase intentions para pengguna kartu simPATI di Kota Pekanbaru. Dalam hal ini customer value dinilai berperan penting bagi repurchase intentions. Disamping itu, customer value berperan penting memperantarai hubungan antara brand loyalty dan brand associations, masingmasing bagi repurchase intentions. Tetapi peran terbaiknya hanya dalam memperantarai hubungan antara brand associations dengan repurchase intentions.

\section{DAFTAR RUJUKAN}

Aaker, D.A. (1989), “Managing assets and skills : the key to a sustainable competitive advantage", California Management Review, Vol,32, Winter, hal.91-106

Aaker, D.A. (1991), "Managing Brand Equity",The Free Press, New York, NY

Aaker, D.A. (1996), "Measuring brand equity across products and markets", California Management Review, Vol.38 No.3, hal 102-120

Aaker, D.A., Kumar, V., dan Day, G.S (1998), "Marketing Research", 6 ${ }^{\text {th }}$ Ed..Jhon Wiley \& Sons, Inc., Canada

Baldauf, A., Cravens, K.S dab Bluder, G (2003), "Performance consequences of Brand equity management :evidance from organizations in the value chain", Journal of Product \& Brand Management, Vol.12 No.4. p. 220-236
Cobb-Walgren, C.J., Ruble, C.A. dan Donthu, N. (1995), "Brand Equirty, brand preference, and purchase intention", Journal of Advertising. Vol. 24 No.3, hal 25 40

Duncan, T. (2002), IMC; "Using advertising \& promotion to build brands", International ed., McGraw-Hill, New York, NY.

Gronroos, Ch. (2000), "Service Management and Marketing; A Customer Relationship Management Approach", $2^{\text {nd }}$ Ed., Jhon Wiley \& Sons, Ltd., Chichester, West Sussex, England.

Grover, R. and Srinivasan, V. (1992), "Evaluating the multiple effect of retail promotions on brand-loyal and brand-switching segments", Journal of Marketing Research, Vol.18, February, hal 76-89.

Hair, J.F.Jr., Anderson, R.E, Tatham, R.L. danBlack.W.C.(1998), "Multivariate Data Analysis", $5^{\text {th }}$ Ed., Prentice Hall, Inc., New Jersey.

Indriantoro, Nur\&Supomo. (2002) , "MetodologiPenelitianBisnisUntuk Akuntansi\&Manajemen”, BPFE Yogyakarta, Yogyakarta

Kashyap, R. danBojanic, D.C. (2006), “A structural analysis of value, quality, and price perceptions of business and leisure travelers", Journal of Travel Research, Vol.39, August, hal $45-51$.

Oliver, R.L, (1997), "Satisfaction: a behavioral perspective on the customer', McGrawHill, New York, NY 
Purba, J.O. (2010), "Peran ekuitas merek pada pembentukan nilai pelanggan produk telepon selular di kota Pekanbaru",Tesis, Program PascaSarjana FE Universitas Riau, Pekanbaru

Simon, C. J, dan Sulivan, M.W. (1993), "The measurement and determinants of brand equity: a financial approach", Marketing Science, Vol.12 No 1, hal. $28-52$.

Srivastava, R.K., dan Shocker, A.D (1993), "Brand Equity: A perspective on its meaning and measurement", Marketing Science Institute Report No 91-124., Marketing Science Institute, Cambridge, MA.

Suryani, Susie. (2006), "Pengaruh ekuitas merek terhadap purchase intention melalui nilai pelanggan pembaca Koran Riau Pos di Pekanbaru",Tesis, Program PascaSarjana FE Universitas Riau, Pekanbaru

Yasir, Sugianto. (2004),“Kontribusi ekuitas merek terhadap pembentukan nilai pelanggan studi pada telepon seluler", Tesis. Program PascaSarjana FE UI Depok
Yoo, B. Donthu, N. (2001), "Developing and validating a multidimensional consumer-based brand equity scale", Journal of Business Research, Vol. 52, hal 1 - 14.

Yusnidar, (2014), "Pengaruh Kepercayaan dan Persepsi Resiko terhadap Minat Beli dan Keputusan Pembelian Produk Fashion secara Online di Kota Pekanbaru",Tesis, Program PascaSarjana FE Universitas Riau, Pekanbaru

Widjaja, dkk. (2007), “Analisis Penelitian Konsumen terhadap Ekuitas Merek Coffe Shops di Surabaya”, Jurnal Manajemen Perhotelan, Vol.3 No.2 September 2007, hal 89-101. , (Annual Report Telkomsel, 2013). 2014

http://www.telkom.co.id/UHI/CDInteraktif 2013/ID/0118_persaingan.html

http://agneskurniawan.wordpress.com/2007 /12/31/perang-ala-kartu-prabayar/ 